\title{
Comércio formal e perfil de consumidores de plantas medicinais e fitoterápicos no município de Itaqui - RS
}

\author{
ETHUR, L.Z.*; JOBIM, J.C.; RITTER, J.G.; OLIVEIRA, G.; TRINDADE, B.S.
}

Curso de Agronomia, Campus de Itaqui, UNIPAMPA, Rua Luiz Joaquim de Sá Britto, s/n, CEP: 97650-000, Itaqui-

Brasil *lucianaethur@unipampa.edu.br

\begin{abstract}
RESUMO: O presente trabalho visou realizar um diagnóstico sobre os consumidores de plantas medicinais e fitoterápicos, abordando também alguns aspectos relacionados à comercialização, no município de Itaqui-RS. A coleta de dados foi efetuada em duas etapas complementares, centrada nos consumidores e estabelecimentos de comercialização, mais especificamente farmácias. Primeiramente diagnosticou-se o perfil dos usuários de plantas medicinais, através de questionário semi-estruturado que foi aplicado a 183 pessoas abordadas em áreas de circulação de moradores de todos os bairros do município; na segunda etapa, avaliou-se a comercialização e visão do comércio formal nas oito farmácias do município. De acordo com os resultados das entrevistas para a construção do perfil dos usuários de plantas medicinais observou-se que $71 \%$ dos entrevistados ficaram na faixa etária de 21 a 60 anos e que a grande maioria apresenta renda mensal de até três salários mínimos; quanto ao uso de plantas na medicina popular, cerca de $82 \%$ afirmaram terem obtido eficiência e que em caso de problemas de saúde $47 \%$ procuram pelas plantas; quanto ao cultivo, $55 \%$ dos entrevistados às cultivam em suas residências. $\mathrm{Na}$ segunda etapa realizada em farmácias, observou-se que a compra de fitoterápicos e plantas medicinais era realizada praticamente por mulheres, das quais $75 \%$ adultas e $25 \%$ idosas. Os chás mais vendidos foram principalmente os emagrecedores e digestivos e o valor gasto com esse tipo de produto ficou na faixa de $R \$ 1,00$ a $R \$ 3,00$. Conclui-se que existe mercado para plantas medicinais e fitoterápicos e necessidade de maiores informações referentes à forma de cultivo, correta identificação botânica, informações ao consumidor, qualidade e eficácia dos produtos e seu uso.
\end{abstract}

Palavras-chave: etnobotânica, farmácias, plantas na terapêutica

ABSTRACT: Formal trade and profile of consumers of medicinal plants and phytomedicine in Itaqui Municipality, Rio Grande do Sul State, Brazil. This study aimed to make a diagnosis of consumers of medicinal plants and phytomedicine, also addressing some aspects related to trade in Itaqui Municipality, Rio Grande do Sul State, Brazil. Data collection was performed in two complementary stages focusing on consumers and stores, especially drugstores. First, the profile of medicinal plant users was diagnosed through a semi-structured questionnaire which was applied to 183 people approached in areas frequently visited by inhabitants from different villages of the municipality; in the second stage, the trade and the view of formal trade was evaluated in the eight drugstores of the municipality. The results of interviews to build the profile of medicinal plant users showed that $71 \%$ interviewees were between 21 and 60 years old and most of them had monthly income of up to three minimum wages; as to the use of plants in folk medicine, around $82 \%$ stated to have had efficiency and, in cases of health problems, $47 \%$ searched for these plants; as regards cultivation, $55 \%$ interviewees cultivated medicinal plants in their houses. The second stage, carried out in drugstores, also indicated that phytomedicines and medicinal plants were purchased mostly by women, $75 \%$ adults and $25 \%$ elderly. The most sold teas were slimming and digestive teas, and the value paid for this type of product was between $R \$ 1.00$ and $R \$ 3.00$. In conclusion, there is market for medicinal plants and phytomedicine and there is also the need for further information related to their cultivation form and proper botanical identification, as well as information to users, quality and efficacy of products, and their use.

Key words: ethnobotany, drugstores, plants in therapeutics

Recebido para publicação em 07/05/2008

Aceito para publicação em 23/12/2010

Rev. Bras. PI. Med., Botucatu, v.13, n.2, p.121-128, 2011. 


\section{INTRODUÇÃO}

As plantas medicinais foram negligenciadas pelo mercado e consumidores, porém na década de 80 essa realidade começou a mudare, atualmente, ocorrem constantes descobertas sobre o uso de plantas na terapêutica e principalmente de novos produtos, devido à pressão sofrida pelo mercado. A complexidade do mundo das plantas medicinais inicia-se na própria definição, pois tradicionalmente se assume que plantas medicinais são vegetais empregados com fins terapêuticos, em função de que ao menos uma das partes possui propriedades medicamentosas (curativas ou preventivas) (Fonte, 2004).

Segundo a Organização Mundial da Saúde $80 \%$ da população mundial faz uso de medicamentos derivados de plantas medicinais. No Brasil pesquisas demonstram que $91,9 \%$ da população fizeram uso de alguma planta medicinal, sendo que $46 \%$ da mesma mantêm cultivo caseiro dessas plantas (ABIFISA, 2007). De acordo com Melo et al. (2007), existe no Brasil uma farmacopéia popular muito diversa baseada em plantas medicinais, resultado da miscigenação cultural envolvendo africanos, europeus e indígenas. Portanto, a construção do perfil local e regional de usuários de plantas medicinais é de extrema importância principalmente com relação à comercialização e a abertura de novos nichos de mercado e de emprego.

Nas últimas duas décadas ocorreu aumento no interesse, pela humanidade, por plantas medicinais e respectivos produtos, acarretando a abertura de mercados nacionais e mundiais na área de fitoterápicos e plantas bioativas. De acordo com Rodrigues \& Carvalho (2007), os raizeiros de Alto Rio Grande-MG reconhecem que ocorreu declínio na procura de plantas medicinais nas décadas de $70 \mathrm{e}$ 80 , retomando por volta de 1985 e intensificando-se cada vez mais até os dias de hoje. O intenso crescimento do mercado de plantas medicinais no Brasil é motivado por diversos fatores, dentre os quais, o consumismo de produtos naturais, acessibilidade para os segmentos de baixa renda e eficácia no tratamento de enfermidades (Santos, 2004; Alves et al., 2007). Não existem dados oficiais a respeito do mercado de plantas medicinais e fitoterápicos no Brasil, principalmente com relação a volume e preço (Alves et al., 2007), porém estima-se um movimento no mercado brasileiro em torno de 1 bilhão de reais/ ano e previsão de que, em 2010, o mercado de fitoterápicos chegará a $15 \%$, do total do mercado farmacêutico (ABIFISA, 2007).

O início do comércio informal de plantas medicinais deve ter ocorrido no momento em que se iniciaram as permutas de mercadorias. O comércio informal, ou seja, aquele que não apresenta qualquer tipo de certificação e/ou licenciamento de prefeituras é realizado por raizeiros, ervateiros e extrativistas, em praticamente todas as cidades brasileiras (Marodin \& Baptista, 2002; Pinto \& Maduro, 2003; Alves et al., 2007; Maioli-Azevedo \& Fonseca-Kruel, 2007; Rodrigues \& Carvalho, 2007). O comércio formal, atualmente, agrega grande variedade de estabelecimentos, tais como, mercados, drogarias, farmácias e feiras, apresentando diversidade de plantas e fitoterápicos (Bello et al., 2002; MaioliAzevedo \& Fonseca-Kruel, 2007; Melo et al., 2007). Os segmentos de agronegócios (conjunto de operações da cadeia produtiva que vai desde a produção até a comercialização) devem observar profundamente as tendências de mercado, para identificar quais os atributos dos bens que têm maior valor sob a ótica do consumidor final, para aproveitar as reais oportunidades (Vilela \& Macedo, 2000). De acordo com o exposto, o objetivo do trabalho foi realizar o diagnóstico do perfil dos usuários de plantas medicinais do município de Itaqui-RS, bem como, a comercialização de plantas medicinais e fitoterápicos em farmácias e a visão do comércio formal com relação aos consumidores nesse município.

\section{MATERIAL E MÉTODO}

\section{Área de estudo}

A presente pesquisa foi desenvolvida no município de Itaqui, localizado na fronteira oeste do Estado do Rio Grande do Sul, que de acordo com a Fundação de Economia e Estatística (2007) apresenta a seguinte caracterização, latitude de 2907'31" sul e longitude 56ㅇ' 11 " oeste, estando a uma altitude de 57 metros; com área (2006) de $3.404 \mathrm{Km}^{2}$; aproximadamente 36 mil habitantes (2007), densidade demográfica (2006) com 10,9 hab km-2, taxa de analfabetismo (2000) de $8,61 \%$, coeficiente de mortalidade infantil (2006) de 5,55 por mil nascidos vivos. Economia baseada praticamente no cultivo do arroz e na pecuária, PIB per capita (2005) R \$ 11.494,00 e PIB pm (2005) mil 487.062 (FEE-RS, 2007), sendo que a maioria da população recebe até três salários mínimos.

\section{Coleta de dados}

A coleta de dados foi efetuada nos meses de maio a julho de 2007, em duas etapas complementares, centrada nos consumidores e nos estabelecimentos de comercialização, mais especificamente farmácias. Foram aplicados questionários semiestruturados e procurou-se estabelecer um esquema padrão de abordagem aos entrevistados.

Na primeira etapa, o questionário (Arnous et al., 2005) foi aplicado no centro do município de Itaqui, em frente ao posto de saúde, prefeitura, praça central, lojas e mercados, onde foram entrevistados 183 transeuntes. Nos locais referidos, podem ser

Rev. Bras. PI. Med., Botucatu, v.13, n.2, p.121-128, 2011. 
encontradas pessoas de todos os bairros do município e de diferentes classes sociais. As entrevistas ocorreram durante dois meses e procurou-se proporção semelhante entre o número de homens (90) e de mulheres (93) por existir a premissa de que as mulheres são as principais usuárias ou aquisitoras de plantas para a terapêutica (Marchese et al., 2004; Arnous et al., 2005), além do predomínio no uso de medicamentos convencionais (Bertoldi et al., 2004). Para o questionário foram elaboradas questões que pudessem fornecer dados para o diagnóstico do perfil dos consumidores de plantas medicinais do município de Itaqui, tais como, sexo, faixa etária, renda, obtenção das plantas, se cultiva e com quem aprendeu a utilizar plantas na terapêutica.

A segunda etapa foi realizada no comércio formal (Bello, 2002; Maioli-Azevedo \& Fonseca-Kruel, 2007; Melo et al., 2007), os dados foram coletados nas oito farmácias do município (100\% dos estabelecimentos farmacêuticos), sendo que três delas integram a rede de farmácias local, uma pertence a rede estadual e duas são de manipulação. Desses estabelecimentos comerciais seis estão localizados no centro e dois em bairros. As entrevistas foram realizadas com os farmacêuticos e atendentes das farmácias, com questionamentos (Marchese et al., 2004) referentes a sexo e idade do consumidor; rotatividade dos produtos; preferência dos consumidores por preço, fabricante ou embalagem; finalidade e produtos mais comercializados dentre fitoterápicos, chás, extratos e medicamentos. Em municípios do porte de Itaqui, os farmacêuticos e atendentes de farmácias conhecem os fregueses que frequentam os estabelecimentos comerciais; vivência completamente diferente dos estabelecimentos comerciais de cidades mais populosas.

A rotatividade dos produtos é dado importante principalmente para o comércio formal de plantas medicinais e produtos. A rotatividade de produtos consiste no número de dias que decorre entre 0 recebimento e o registro da mercadoria (estoque) e a data da saída (Femenick, 2008), quanto menor o tempo (em dias) que o produto fica armazenado, maior é a rotatividade.

Nos questionários foram abordados alguns termos que necessitam ser definidos, tais como, fitoterápicos, chás, extratos e medicamentos. Os fitoterápicos são medicamentos obtidos a partir de plantas medicinais (BRASIL, 2003) e nos quais são empregados exclusivamente derivados de vegetais (extrato, tintura, óleo, cera, exsudato, suco e outros) e não é objeto de registro como medicamento fitoterápico, planta medicinal ou suas partes. Os produtos tidos como fitoterápicos nas farmácias foram xaropes, sachês de mel (mais plantas medicinais variadas), balas, cápsulas e sprays bucais.

Para os chás utilizam-se plantas destinadas à preparação de infusões e decocções (BRASIL,
2003), constituídos por folhas, caules, raízes, flores e/ou inflorescências secas (plantas beneficiadas). Eles são comercializados em embalagens plásticas transparentes de tamanhos variados de acordo com a quantidade do produto e em sachês.

Outros produtos avaliados foram os extratos, que são preparações de consistências líquida, sólida ou intermediária, obtidas a partir do material vegetal. Os extratos são preparados por percolação, maceração ou outro método adequado e validado, utilizando como solvente etanol, água ou outro solvente adequado (BRASIL, 2005). Esses produtos são encontrados em embalagens plásticas e vidro (encontrados em farmácias de manipulação).

Por fim, os medicamentos que são produtos farmacêuticos, tecnicamente obtidos ou elaborados, com finalidade profilática, curativa, paliativa ou para fins de diagnóstico (BRASIL, 1973). Comercializados como pomadas, cápsulas e variadas embalagens plásticas e de vidro.

\section{RESULTADO E DISCUSSÃO}

Na primeira etapa do estudo realizado com a população do município de Itaqui, observou-se que dos 183 entrevistados, 71\% (131 pessoas) afirmaram fazer uso de plantas medicinais enquanto 29\% não as utilizam. Dos usuários, com relação à faixa etária, o predomínio foi de 21 a 60 anos (67\%) (Figura 1A); sendo essa faixa predominante em estudo referente aos consumidores de plantas medicinais e condimentares no município de Pato Branco-PR, que segundo Marchese et al. (2004) é a faixa de idade considerada economicamente ativa. O predomínio de usuários de plantas na terapêutica, na faixa etária entre 20 e 69 anos, também foi observado por Arnous et al. (2005), em pesquisa realizada no município de Datas-MG.

A partir das entrevistas, observou-se que $85 \%$ dos entrevistados que utilizam plantas na terapêutica encontram-se na faixa de 0 a 3 salários mínimos (85\%) (Figura 1B), evidenciando economia de baixa renda entre a maior parte dos entrevistados. Resultado semelhante foi encontrado por Arnous et al. (2005), que entre 0 a 3 salários mínimos encontraram 0 equivalente a $93 \%$ dos entrevistados no município de Datas-MG.

Dos entrevistados que utilizam plantas medicinais, observou-se que $54 \%$ eram mulheres e $46 \%$ homens, evidenciando equiparação entre os sexos. Entretanto, em farmácias de Belo HorizonteMG, comprovou-se maior aceitabilidade do uso de fitoterápicos pelas mulheres (75\%) (Ribeiro et al., 2005). Além de fitoterápicos e plantas medicinais foi relatado por Bertoldi et al. (2004), que em Pelotas$\mathrm{RS}$ as mulheres apresentaram prevalência na utilização de medicamentos, superior em $20 \%$ aos homens (eliminando o uso de contraceptivos).

Rev. Bras. PI. Med., Botucatu, v.13, n.2, p.121-128, 2011. 

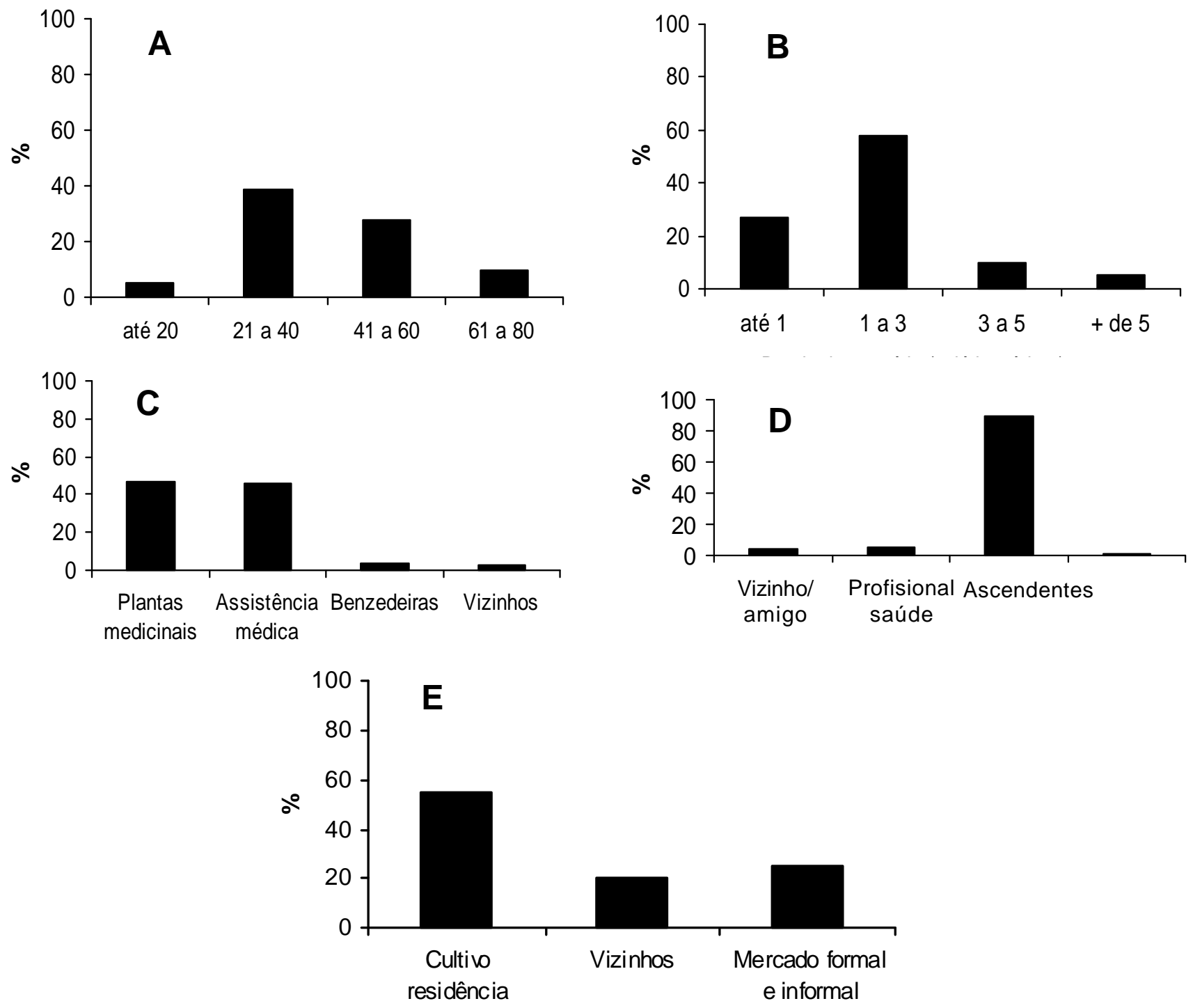

FIGURA 1. Perfil de usuários de plantas medicinais, em Itaqui - RS. A. Faixa etária (em anos) dos usuários de plantas medicinais; B. Renda (salário mínimo nacional) dos usuários de plantas medicinais; C. Recursos utilizados em caso de problemas de saúde; D. Aprendizado sobre plantas na terapêutica; E. Obtenção de plantas medicinais.

Quanto aos recursos utilizados em caso de problemas de saúde, $47 \%$ dos entrevistados procuram por plantas medicinais (Figura 1C) em detrimento de outros recursos e $82 \%$ afirmaram terem obtido resultados positivos com o uso das mesmas. Resultados semelhantes foram encontrados para 0 município de Datas-MG, onde 66\% dos entrevistados procuram por plantas medicinais em caso de doença e 83\% afirmaram terem obtido resultados satisfatórios com o uso (Arnous et al., 2005).

Cerca de $90 \%$ dos entrevistados aprenderam a utilizar plantas medicinais com seus ascendentes (Figura 1D), sendo que para o município de DatasMG, o percentual de entrevistados que confirmaram esse aprendizado foi de 84,5\% (Arnous et al., 2005). Verificou-se que o aprendizado sobre plantas na terapêutica é passado de geração a geração, também, no município de Dom Pedro de Alcântara-RS (Marodin \& Baptista, 2002). Além dos usuários, pode-se ressaltar que os próprios comerciantes (raizeiros) de Boa Vista-RR confirmam que a maior parte dos conhecimentos foi repassada, principalmente, por pais e avós (Pinto \& Maduro, 2003), o mesmo ocorrendo entre os raizeiros da microrregião do Alto Rio Grande$M G$, todos descendentes de avós indígenas, africanos ou ambos (Rodrigues \& Carvalho, 2007). De acordo com a pesquisa sobre como o conhecimento é gerado, transformado e apropriado por diferentes profissionais ligados às plantas medicinais e fitoterápicos, Rezende \& Ribeiro (2005) relataram que existe a busca da ancestralidade pelo saber tradicional com relação ao uso de plantas medicinais. 
Esse saber, atualmente, é transformado na maior parte das vezes em produtos, porque os setores industriais e os grandes atacadistas buscam por novidades constantemente, embasados na maior aceitação e consumo pela sociedade.

Das pessoas entrevistadas, $55 \%$ cultivam as plantas medicinais em suas residências e somente $25 \%$ compram no mercado formal e informal (Figura $1 \mathrm{E})$. Dados referentes à percentagem de pessoas que cultivam ou compram plantas medicinais no mercado formal e informal divergem de acordo com as diferentes realidades e características de cada município. Para o município de Mogi-Mirim-SP, 54\% dos entrevistados cultivam plantas medicinais e $11,5 \%$ compram no mercado formal (Pilla et al., 2006). Entretanto, para o município de Datas-MG, $78,5 \%$ das pessoas entrevistadas possuem o hábito de cultivar as plantas em seus quintais e apenas $3 \%$ compram no mercado formal e informal.

Quando indagados a respeito do interesse no cultivo, $74 \%$ das pessoas mostraram-se interessadas em cultivar plantas bioativas nas residências, sendo que dessas, $55 \%$ já as cultivam (Figura 1E). Portanto, a produção de mudas, substratos e utensílios para o cultivo de plantas medicinais é um setor de mercado que pode vir a ser explorado, inclusive, pela agricultura peri-urbana, no município de Itaqui.

$\mathrm{Na}$ segunda etapa do estudo, realizada em farmácias de Itaqui observou-se que a compra de fitoterápicos e plantas medicinais é realizada $100 \%$ por mulheres. Resultados semelhantes foram encontrados para a cidade de Pato Branco-PR, com $78 \%$ das compras de plantas medicinais e condimentares em mercados sendo realizadas por mulheres (Marchese et al., 2004) e em Belo Horizonte-MG, no contingente de $75 \%$ dos consumidores entrevistados em farmácias (Ribeiro et al., 2005). As mulheres são as que mais compram, entretanto, isso não quer dizer que os homens não utilizem fitoterápicos e/ou plantas na terapêutica.

Com relação a faixa etária das pessoas que adquirem plantas medicinais e fitoterápicos, a pesquisa ressaltou que as compras são realizadas por $75 \%$ de adultos (entre 18 e 61 anos) e $25 \%$ de idosos (acima de 61 anos). Segundo Ribeiro et al. (2005) $61 \%$ dos consumidores entrevistados em farmácias de Belo Horizonte-MG estão na faixa etária de 30 a 59 anos e apenas $10 \%$ acima de 60 anos. Para os raizeiros de Boa Vista-RR, no comércio informal, o usuário se caracteriza por ser sempre adulto com idade superior a 18 anos (Pinto \& Maduro, 2003). Entretanto, pode-se fazer a ressalvar de que os idosos, na maior parte das vezes, não fazem compras, sendo essas realizadas por pessoas mais jovens, fato que não pode desvinculá-los do uso dos produtos mencionados.

Com relação aos produtos mais comercializados nas farmácias e nas farmácias de manipulação (Figura 2A) ficou comprovado que além dos medicamentos, as plantas medicinais e produtos são adquiridos pela população. Os chás mais procurados, de acordo com as farmácias, são aqueles utilizados principalmente como emagrecedores e digestivos (Figura 2B). A utilização como digestivo foi indicada em outras pesquisas, como um dos principais motivos para o uso de plantas medicinais, dentre as quais, Jacoby et al. (2002), no município de Irati-PR; Marodin \& Baptista (2002), no município de Dom Pedro de Alcântara-RS e Pilla et al. (2006), em Mogi-Mirim-SP.

Para os chás emagrecedores, pode-se ressaltar que na última década o peso corporal "ideal" passou a ser um objetivo, principalmente para as mulheres. Em matéria, na mídia impressa, Poyastro (2007) relata que os chás emagrecedores são os mais vendidos no Mercado Público em Porto Alegre-RS. Entretanto, deve-se ter cuidado com a utilização dos chás emagrecedores, assim como de quaisquer outros, para vários fins, porque, segundo Ernst \& Pittler (1998), ocorreram mortes de mulheres que realizaram tratamentos para emagrecer devido à presença de um ácido da Aristolochia fangchi (Y.C. Wu ex L.D. Chow \& S.M. Hwang). Em avaliações de bulas de fitoterápicos em farmácias de Porto Alegre$\mathrm{RS}$, constatou-se que um dos problemas detectados era a grande quantidade de bulas com indicações para regimes de emagrecimento e para redução de celulite, principalmente nos produtos contendo sene (Cassia angustifolia Vahl.) e alcachofra (Cynara scolymus L.), ocorrendo muitas vezes informações não fidedignas (Bello et al., 2002).

Não foram encontradas indicações para uso terapêutico dos chás nas embalagens, de acordo com o recomendando pela ANVISA (BRASIL, 1998), entretanto as mesmas eram disponibilizadas em folhetos, disponíveis nos balcões das farmácias, sendo que o consumidor poderia não ter conhecimento da existência. De acordo com pesquisas realizadas em mercados e farmácias da cidade de Recife-PE, de todos os produtos comercializados a base de boldo (Peumus boldus Molina), pata-de-vaca (Bauhinia spp.) e ginco (Ginkgo biloba L.), apenas $4 \%$ portavam bula e informações obrigatórias (Melo et al., 2004) e de produtos a base de castanha-da-índia (Aesculus hippocastanum L.), capim-limão (Cymbopogon citratus (DC.) Stapf) e centela (Centella asiatica (L.) Urban), apenas 18\% possuíam as informações em bula e 7\% portavam informações técnico-científicas exigidas pela legislação de maneira irrepreensível (Melo et al., 2007). O uso indiscriminado de produtos à base de plantas medicinais, sem orientações médicas, com indicações duvidosas, pode se perigoso para a população, sendo muitas vezes, agravado pela falta de informações fidedignas (Bello et al., 2002).

Rev. Bras. PI. Med., Botucatu, v.13, n.2, p.121-128, 2011. 


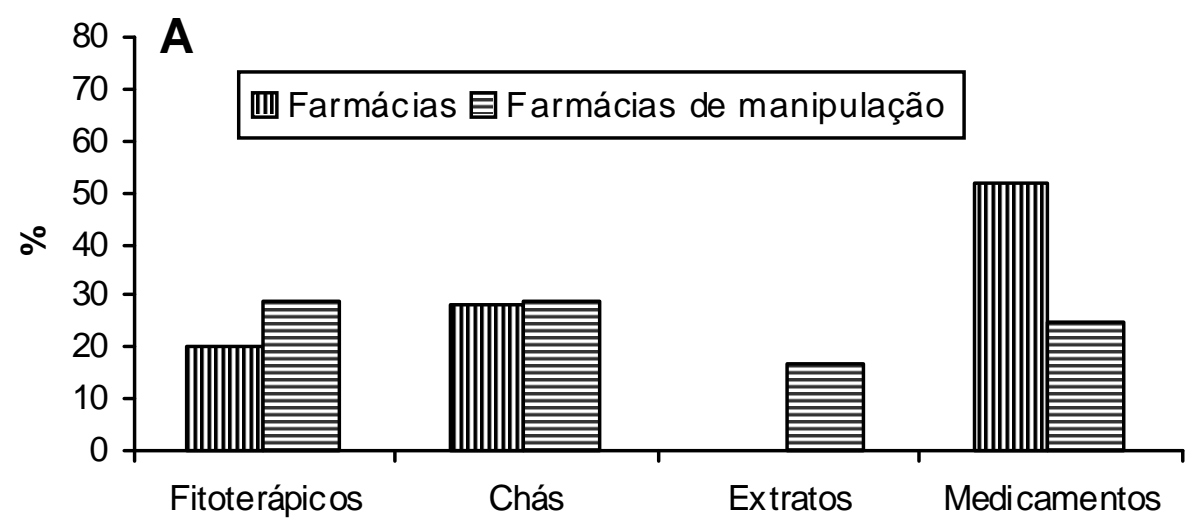

Produtos comercializados

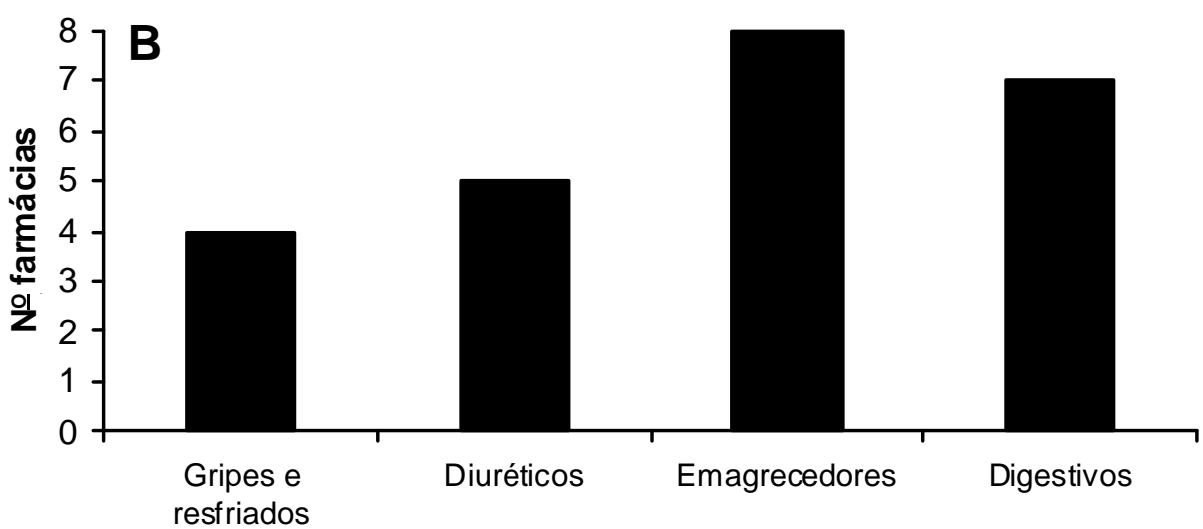

Finalidade

FIGURA 2. Dados referentes às entrevistas sobre plantas medicinais e fitoterápicos, realizadas nas farmácias, em Itaqui - RS. A. Produtos comercializados nas farmácias; B. Finalidade dos chás mais comercializados nas farmácias.

Observou-se que o valor gasto com produtos de plantas medicinais nas farmácias está, em cerca de $90 \%$ dos casos, na faixa de $R \$ 1,00$ a $R \$ 3,00$ e apenas em $10 \%$ dos mesmos, na faixa de mais de $\mathrm{R} \$ 3,00$ (em média de vendas). No mercado informal, em Boa Vista-RR o valor médio gasto com plantas medicinais foi de $R \$ 1,00$ a $R \$ 5,00$, de acordo com raizeiros locais (Pinto e Maduro, 2003); na região de Alto Paraíso de Goiás-GO, os preços variam de acordo com o produto apresentado pelos raizeiros, os chás na faixa de $R \$ 5,00$ a $R \$ 10,00$, pomadas no valor de $R \$ 5,00$, sabonetes $R \$ 3,00$, dentre outros (Souza \& Felfili, 2006). Entretanto, o preço dos produtos contendo plantas medicinais é bem inferior aos medicamentos industrializados (Alves et al., 2007) e acredita-se que devido a esses valores serem acessíveis à população, $75 \%$ dos produtos apresentam rotatividade média (os produtos permanecem por curto período de tempo em estoque) e $12,5 \%$ rotatividade alta (os produtos praticamente não permanecem em estoque) nas farmácias de Itaqui. A rotatividade dos produtos a base de plantas medicinais, ou seja, a compra e venda constante de determinados produtos e de novos produtos, pelos estabelecimentos comerciais no município de Itaqui, sugere a existência de mercado na cadeia produtiva de plantas medicinais e fitoterápicos e que pode vir a ser explorado.

As razões para a compra dos fitoterápicos e plantas medicinais relacionam-se a acessibilidade dos preços e o fabricante, não estando relacionadas à apresentação, pois não existe procura pelo tipo de embalagem. Menor preço também foi citado por Marchese et al. (2004) como sendo fator prioritário para a compra de plantas medicinais e condimentares em mercados, na cidade de Pato Branco-PR. Segundo Santos (2004), o crescimento do mercado de plantas medicinais ocorre devido a diversos aspectos, dentre os quais, a acessibilidade, principalmente para os segmentos sociais de baixa renda.

A preocupação, por parte do consumidor, com relação ao fabricante ou empresa responsável pelo produto (e não somente com relação ao preço) é fator importante, pois demonstra que a qualidade do produto comercializado deve ser rigorosamente controlada. Pesquisas realizadas em mercados e farmácias na cidade de Recife-PE, demonstraram que todos os fitoterápicos a base de boldo e pata-de-vaca podem oferecer riscos ao usuário, uma vez que não estão adequados às exigências sanitárias (Melo et 
al., 2004); e produtos a base de centela e alguns a base de castanha-da-índia e capim-limão podem oferecer riscos ao consumidor e/ou ausência de eficácia devido ao elevado teor de impurezas encontradas (Melo et al., 2007).

Contudo, os dados levantados neste estudo permitem uma melhor compreensão de alguns elos da cadeia produtiva de plantas medicinais e fitoterápicos evidenciando que existe mercado e necessidade de maiores informações a respeito do uso desses produtos pela comunidade do município de Itaqui.

Existe mercado tanto para a comercialização de produtos como chás e partes de plantas medicinais in natura ou desidratadas, quanto para produção de mudas, substratos e utensílios visando o cultivo dessas plantas pela população.

Os produtos de plantas medicinais e fitoterápicos indicados como emagrecedores e digestivos são o principal foco do comércio formal, devido a procura por mulheres situadas na faixa etária considerada economicamente ativa na sociedade. Porém, existe necessidade de maiores informações sobre o uso desses produtos para os fins citados.

Constatou-se que o uso por parte da comunidade local de plantas medicinais ocorre devido ao conhecimento acumulado ao longo de gerações, porém há necessidade de estudos em diferentes áreas relacionadas às plantas utilizadas na terapêutica devido ao amplo uso pela população e pelas indagações realizadas pelos entrevistados, referentes à forma de cultivo, correta identificação botânica, informações ao consumidor, qualidade e eficácia dos produtos e uso.

\section{REFERÊNCIA}

ALVES, R.R.N. et al. Utilização e comércio de plantas medicinais em Campina Grande, PB, Brasil. Revista Eletrônica de Farmácia, v.4, n.2, p.175-98, 2007. Disponível em: <http:www.farmacia.ufg.br/revista/geral/ home.htm>. Acesso em: 10 fev. 2007.

ARNOUS, A.H.; SANTOS, A.S.; BEINNER, R.P.C. Plantas medicinais de uso caseiro - conhecimento popular e interesse por cultivo comunitário. Revista Espaço para a Saúde, v.6, n.2, p.1-6, 2005.

ASSOCIAÇÃO BRASILEIRA DAS EMPRESAS DO SETOR DE FITOTERÁPICOS, SUPLEMENTO ALIMENTAR E DE PROMOÇÃO DA SAÚDE - ABIFISA. Introdução. 2007. Disponível em: <http://www.abifisa.org.br>. Acesso em: 20 mai. 2007.

BELLO, C.M.; MONTANHA, J.A.; SCHENKEL, E.P. Análise das bulas de medicamentos fitoterápicos comercializados em Porto Alegre, RS, Brasil. Revista Brasileira de Farmacognosia, v.12, n.2, p.75-83, 2002.

BERTOLDI, A.D. et al. Utilização de medicamentos em adultos: prevalência e determinantes individuais. Revista de Saúde Pública, v.38, n.2, p.228-38, 2004. BRASIL. Ministério da Saúde. Agência Nacional de
Vigilância Sanitária. Lei no 5.991, de 17 de dezembro de 1973. Conceitos técnicos. Disponível em: <http://www. anvisa.gov.br>. Acesso em: 20 mai. 2007.

BRASIL. Ministério da Saúde. Agência Nacional de Vigilância Sanitária. Portaria 519, de 16 de setembro de 1998. Disponível em: <http://www.anvisa.gov.br>. Acesso 20 mai. 2007.

BRASIL. Ministério da Saúde. Agência Nacional de Vigilância Sanitária. Informe Técnico no 7, de 9 de maio de 2003. Disponível em: <http://www.anvisa. gov.br>. Acesso em: 20 mai. 2007.

BRASIL. Ministério da Saúde. Agência Nacional de Vigilância Sanitária. Consulta Pública no 98, de 26 de dezembro de 2005 (Anexo II). Disponível em: <http:// www.anvisa.gov.br>. Acesso em: 20 mai. 2007.

ERNST, E.; PITTLER, M.H. Risks associated with herbal medicinal products. Wiener Medizinische Wochenschrift, v.152, n.7-8, p.183-9, 1998.

FEMENICK, T.R. Considerações sobre a rubrica estoques. Disponível em: <http://www.tomislav.com.br/ sala_de_aula/auditoria.php>. Acesso em: 20 jul. 2007. FONTE, N.N. A complexidade das plantas medicinais: enfoque farmacêutico. In: CORREA JUNIOR, C.; GRAÇA, L.R.; SCHEFFER, M.C. Complexo agroindustrial das plantas medicinais, aromáticas e condimentares do Estado do Paraná: diagnóstico e perspectivas. Colombo: EMBRAPA Florestas, 2004. p.24-46.

FUNDAÇÃO DE ECONOMIA E ESTATÍSTICA - FEE. Secretaria do Planejamento e Gestão. Governo do Rio Grande do Sul. Disponível em: <htpp://www.fee.tche.br/ sitefee/pt/content/resumo/pg_municipios_detalhe. php?municipio=Itaqui>. Acesso em: 25 ago. 2007.

JACOBY, C. et al. Plantas medicinais utilizadas pela comunidade rural de Guamirim, Município de Irati, PR. Revista Ciências Exatas e Naturais, v.4, n.1, p.79-89, 2002.

MAIOLI-AZEVEDO, V.; FONSECA-KRUEL, V.S. Plantas medicinais e ritualísticas vendidas em feiras livres no município do Rio de Janeiro, RS, Brasil: estudo de caso nas zonas Norte e Sul. Acta Botanica Brasilica, v.21, n.2, p.263-75, 2007

MARCHESE, J.A. et al. Perfil dos consumidores de plantas medicinais e condimentos do município de Pato Branco (PR). Horticultura Brasileira, v.22, n.2, p.332-5, 2004.

MARODIN, S.M.; BAPTISTA, L.R.M. Plantas medicinais do município de Dom Pedro de Alcântara, Estado do Rio Grande do Sul, Brasil: espécies, famílias e usos em três grupos da população humana. Revista Brasileira de Plantas Medicinais, v.5, n.1, p.1-9, 2002.

MELO, J.G. et al. Avaliação da qualidade de amostras comerciais de boldo (Peumus boldus Molina), pata-devaca (Bauhinia spp.) e ginco (Ginkgo biloba L.). Revista Brasileira de Farmacognosia, v.14, n.2, p.111-20, 2004. MELO, J.G. et al. Qualidade de produtos a base de plantas medicinais comercializados no Brasil: castanha-da-índia (Aesculus hippocastanum L.), capim-limão (Cymbopogon citratus (DC.) Stapf) e centela (Centella asiatica (L.) Urban). Acta Botanica Brasilica, v.21, n.1, p.27-36, 2007. PILLA, M.A.C.; AMOROZO, M.C.M.; FURLAN, A. Obtenção e uso das plantas medicinais no distrito de Martim Francisco, Município de Mogi-Mirim, SP, Brasil, Acta Botanica Brasilica, v.20, n.4, p.789-802, 2006. 
PINTO, A.A.C.; MADURO, C.B. Produtos e subprodutos da medicina popular comercializados na cidade de Boa Vista, Roraima. Acta Amazonica, v.33, n.2, p.281-90, 2003.

POYASTRO, M. Plantas medicinais podem prejudicar saúde. Correio do Povo, 25 nov. 2007. Cad. Geral, p.15. REZENDE, E.A.; RIBEIRO, M.T.F. Conhecimento tradicional, plantas medicinais e propriedade intelectual: biopirataria e bioprospecção? Revista Brasileira de Plantas Medicinais, v.7, n.3, p.37-44, 2005.

RIBEIRO, A.Q.; LEITE, J.P.V.; DANTAS-BARROS, A.M. Perfil de utilização de fitoterápicos em farmácias comunitárias de Belo Horizonte sob a influência da legislação nacional.

Revista Brasileira de Farmacognosia, v.15, n.1, p.65-
70, 2005.

RODRIGUES, V.E.G.; CARVALHO, D.A. Levantamento etnobotânico de plantas medicinais no domínio dos cerrados na região do Alto Rio Grande - Minas Gerais. Revista Brasileira de Plantas Medicinais, v.9, n.2, p.1735, 2007.

SANTOS, K.S. O mercado de plantas medicinais. Cesubra Scientia, v.1, n.1, p.9-14, 2004.

SOUZA, C.D.; FELFILI, J.M. Uso de plantas medicinais na região de Alto Paraíso de Goiás, GO, Brasil. Acta Botanica Brasilica, v.20, n.1, p.135-42, 2006.

VILELA, N.J.; MACEDO, M.M.C. Fluxo de poder no agronegócio: o caso das hortaliças. Horticultura Brasileira, v.18, n.2, p.88-94, 2000. 